Article

\title{
Carbon Dynamics in the Northeastern Qinghai-Tibetan Plateau from 1990 to 2030 Using Landsat Land Use/Cover Change Data
}

\author{
Jingye $\mathrm{Li}^{1,2}$, Jian Gong ${ }^{1,3, *}$, Jean-Michel Guldmann ${ }^{2} \mathbb{C}$, Shicheng $\mathrm{Li}^{1,4}{ }^{10}$ and Jie Zhu ${ }^{1}$ \\ 1 Department of Land Resource Management, School of Public Administration, \\ China University of Geosciences, Wuhan 430074, China; jingye.li@cug.edu.cn (J.L.); lisc@cug.edu.cn (S.L.); \\ 20141000819@cug.edu.cn (J.Z.) \\ 2 Department of City and Regional Planning, The Ohio State University, Columbus, OH 43210, USA; \\ guldmann.1@osu.edu \\ 3 Key Laboratory of Law Evaluation of Ministry of Land and Resources of China, 388 Lumo Road, \\ Hongshan District, Wuhan 430074, China \\ 4 Key Laboratory of Meteorological Disaster of Ministry of Education, Nanjing University of Information \\ Science and Technology, Nanjing 210044, China \\ * Correspondence: gongjian@cug.edu.cn; Tel.: +86-027-6788-3288
}

Received: 27 December 2019; Accepted: 3 February 2020; Published: 6 February 2020

check for updates

\begin{abstract}
Land use/cover change (LUCC) has an important impact on the terrestrial carbon cycle. The spatial distribution of regional carbon reserves can provide the scientific basis for the management of ecosystem carbon storage and the formulation of ecological and environmental policies. This paper proposes a method combining the CA-based FLUS model and the Integrated Valuation of Ecosystem Services and Trade-offs (InVEST) model to assess the temporal and spatial changes in ecosystem carbon storage due to land-use changes over 1990-2015 in the Qinghai Lake Basin (QLB). Furthermore, future ecosystem carbon storage is simulated and evaluated over 2020-2030 under three scenarios of natural growth (NG), cropland protection (CP), and ecological protection (EP). The long-term spatial variations in carbon storage in the QLB are discussed. The results show that: (1) Carbon storage in the QLB decreased at first (1990-2000) and increased later (2000-2010), with total carbon storage increasing by $1.60 \mathrm{Tg} C$ (Teragram: a unit of mass equal to $10^{12} \mathrm{~g}$ ). From 2010 to 2015 , carbon storage displayed a downward trend, with a sharp decrease in wetlands and croplands as the main cause; (2) Under the NG scenario, carbon reserves decrease by $0.69 \mathrm{Tg} C$ over 2020-2030. These reserves increase significantly by $6.77 \mathrm{Tg} C$ and $7.54 \mathrm{Tg} C$ under the $\mathrm{CP}$ and EP scenarios, respectively, thus promoting the benign development of the regional ecological environment. This study improves our understanding on the impact of land-use change on carbon storage for the QLB in the northeastern Qinghai-Tibetan Plateau (QTP).
\end{abstract}

Keywords: ecosystem services; carbon storage; InVEST model; CA-based FLUS model; Qinghai-Tibetan Plateau

\section{Introduction}

Global climate change has greatly affected ecosystem patterns and processes, which have also been spurred by human activities [1,2]. With accelerated urbanization, land use/cover change (LUCC) has had a significant impact on ecosystem functions, which has become one of the most critical issues in ecosystem and land science research [3-5]. Changes in regional ecosystem carbon storage have a profound influence on the global carbon cycle and atmospheric $\mathrm{CO}_{2}$ concentrations, as carbon sequestration plays a crucial role in reducing the concentration of greenhouse gases. Organic carbon 
storage in the soil affects climate regulation, and is an important issue in global climate change research [6-8].

Methods used to quantify carbon reserves include field surveys [9], modeling [10,11], and remote sensing (RS) [12]. Model-based methods are becoming more important because of their ability to spatially assess carbon reserves at various scales: global [13], national [14,15], regional [16], and city and county [12,17]. For example, one study [18] shows that the impact of land-use change on carbon storage is related to the natural process of soil carbon storage evolution in the floodplains of the Cosmons and California Rivers. A process-based dynamic land ecosystem model is used to simulate vegetation and soil carbon storage in the southern United States, and to assess the carbon dynamics of urbanized land over 1945-2007 [19]. Global urban land and cropland changes from 2000 to 2015 are simulated, and the impacts of these changes on regional carbon storage in different countries and regions are assessed with the Integrated Valuation of Ecosystem Services and Trade-offs (InVEST) model [20], an ecosystem assessment tool jointly developed by Stanford University, the World Wide Fund for Nature (WWF), and The Nature Conservation (TNC) [21]. The InVEST model can be used to quantitatively analyze a variety of ecosystem service functions [21] (e.g., habitat quality, carbon storage, water yield and water provision service, etc.), and to present the assessment results in the form of thematic maps. However, most of these studies focus on the carbon storage of a single ecosystem, for instance, woodland, cropland, grassland, wetland, water, or other single ecosystems [22]. There are few systematic studies on carbon storage by terrestrial ecosystems. Also, most such studies are biased toward single-year explorations [23-25]. One study assesses soil organic carbon storage following conversion from croplands to grasslands [26]. Analyses of carbon reserves in Brazil model and map soil organic matter $[27,28]$, but they focus on the assessment and prediction of soil organic matter $[29,30]$. Few studies predict and simulate future total carbon storage in terrestrial ecosystems. Therefore, model-based assessment of the potential impact of future land-use changes on regional carbon storage is very important, and so is the construction of a long-time carbon storage database of a whole ecosystem for dynamic monitoring and ecological protection. Few models can predict the potential impact of land-use change on carbon storage in the future. To address this gap, we use a land-use change model and an ecosystem system model to assess future ecosystem carbon stocks.

In recent years, there has been more emphasis on models that multiply the average carbon density of each land use/cover (LUC) type by its corresponding area, due to their simplicity of use at different scales [31,32]. A cellular automata (CA) model has strong spatial computing abilities and can effectively simulate and spatially display complex dynamic systems. However, due to the high complexity of the land system, the most difficult aspect in designing CA models is the formulation of cellular transformation rules. In practice, this formulation often relies on expert knowledge, and thus lacks objective standards. The artificial neural network (ANN), an artificial intelligence (AI) technology, has unique nonlinear processing abilities, and can be used to alleviate CA design difficulties. Using ANN and CA is an effective way to simulate land-use change. Almeida and Gleriani successfully apply ANN-based CA from the watershed scale to the urban land-use scale in Piracicaba, Brazil [33]. Li et al. [34] propose an ANN-CA model focusing on the conversion of non-urban to urban land use at a regional scale, and account for three categories of spatial variables: distance, neighbor state, and natural attribute of land use. Several scholars have tried to combine ANN with CA for simulation experiments, but most of their simulated objects are urban areas, with a focus on urban expansion. There is little research on LUCC and ecosystem services in fragile ecological environments. To effectively assess the potential effects of LUCC on carbon storage, we use the ANN-CA and InVEST models, which are both suitable to assess different policy scenarios. First, we describe the principles of the ANN-CA and InVEST models. Second, the two models are implemented as follows: (1) The ANN-CA model is used to predict LUCC resulting from different development scenarios in the QLB; (2) The InVEST model is used to assess carbon storage changes due to LUCC. The carbon density data required in the InVEST model is determined by consulting the related literature. 
In this paper, we focus on the impact of LUCC on the ecosystem service of carbon storage in the Qinghai Lake Basin (QLB) of the Qinghai-Tibetan Plateau (QTP). More than 69\% of the area is grasslands. The $4,500 \mathrm{~km}^{2}$ of Qinghai Lake are teeming with rare aquatic animals (Qinghai Lake naked carp) unique to the plateau, and with more than 300,000 migratory birds living there. This ecosystem is fragile and very sensitive to global change and human intervention. As a result, its environmental conditions have changed significantly over the past decades, including grassland and permafrost degradation, and carbon reserve loss. The QLB is a transitional zone from the arid area of Northwest China to the alpine area of the QTP; it is also the source of some large rivers in China [35] and is sensitive to global climate change. Qinghai Lake is an important ecological body of water on the QTP, and plays a protective role in the desertification of the whole western Qinghai, as well as an important barrier to maintain the ecological security of the northeastern QTP. It is also an important, ecologically fragile area in Western China [36], and its impact on ecosystem carbon storage is still unclear. The Planning of the Main Functional Areas of Qinghai Province lists the QLB as an important part of its ecological security strategy [37]. The region needs to further expand green spaces and enhance its carbon sequestration capacity to respond to global climate change. Therefore, an assessment of ecosystem carbon storage in this area is urgently needed for decisions on land-use, ecological environmental protection, and coordinated sustainable development in the QLB.

This paper takes the QLB as a case study to make the following research contributions to the existing literature:

(1) Analysis of the trends of LUCC and carbon storage in the QLB from 1990 to 2015.

(2) Simulation of land-use changes and carbon storage over 2020-2030 under different scenarios using an ANN-CA model.

\section{Materials and Methods}

\subsection{Study Area and Data}

Located in the northeastern margin of the QTP, the QLB is located in north-central Qinghai Province, ranging from $36^{\circ} 00^{\prime} \mathrm{N}-38^{\circ} 15^{\prime} \mathrm{N}$ to $99^{\circ} 50^{\prime} \mathrm{E}-102^{\circ} 40^{\prime} \mathrm{E}$, with a typical continental plateau climate and a total area of 55.7 million $\mathrm{km}^{2}$ (Figure 1). The QLB is located within the administrative jurisdiction of three prefectures and four counties in Qinghai Province: Haiyan County and Gangcha County in Haibei Tibetan Autonomous Prefecture, Tianjun County in Haixi Mongolian Tibetan Autonomous Prefecture, and Gonghe County in Hainan Tibetan Autonomous Prefecture. Qinghai Lake is the largest saltwater lake in China, with an average altitude of $3193 \mathrm{~m}$. It is surrounded by vast grasslands and many snow peaks, and is an important world wetland [38].

The land-use data are produced using Landsat TM 5 and 7 remote sensing (RS) images (spatial resolution of $30 \mathrm{~m}$ ) for 1990, 2000, 2010, and 2015, with orbital numbers 132, 133, 134, 135, and line numbers 33, 34, and 35. These satellite images were downloaded from the website of the United States Geological Survey (http://earthexplorer.usgs.gov). Images were calibrated by systematic radiation and geometry. Using the Environment for Visualizing Images (ENVI) software, we first established the interpretation marks of ground objects for these RS images, using field surveys and statistical yearbook data. Then, we visually interpreted and reclassified LUC types into cropland, grassland, woodland, construction land, wetland, water area, and unused land. We use Google images and high-resolution images (SPOT 6 with $1.5 \mathrm{~m}$ resolution) to help us in the visual interpretation from the Landsat TM/ETM+ data.

To verify the accuracy of the LUC data, 500 validation samples (Figure S1) were randomly selected from a high-resolution classification map (SPOT 6), and were investigated through a field survey in 2015. The data for 2020-2030 is simulated by the ANN-CA model, which can be synthesized based on the trends of historical LUCC (using the spatial characteristics of recent LUCC and coupling human and natural effects). The probability of occurrence of each type of LUC is used to trace the area's history and predict future land-use change. 


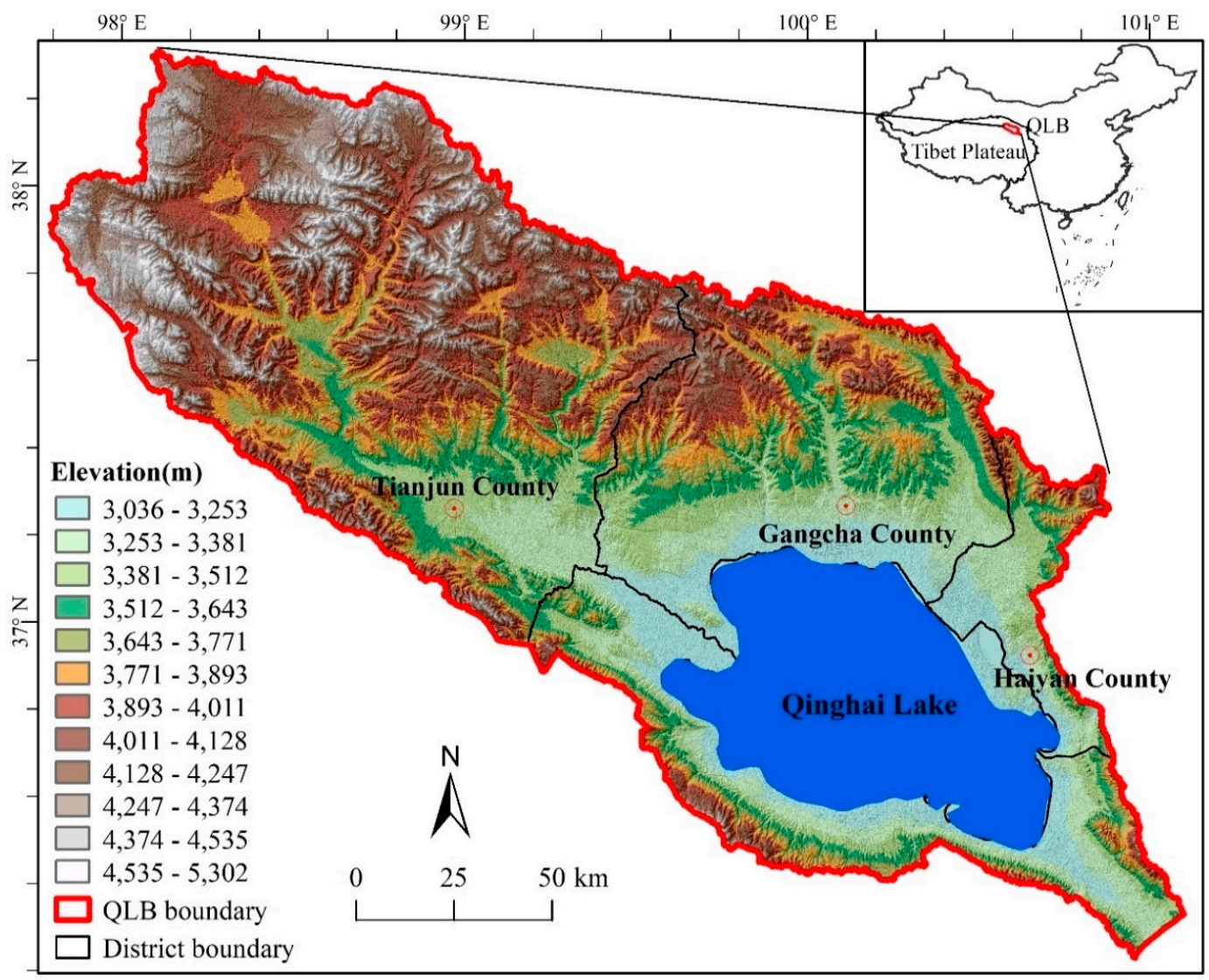

Figure 1. Map of the study area (The elevation data is provided by International Scientific \& Technical Data Mirror Site, Computer Network Information Center, Chinese Academy of Sciences (http://www.gscloud.cn). The vector boundary data for counties are provided by the Data Center for Eco-environment Protection in the Qinghai Lake Basin (http://deep.qherc.org//)).

We set the land demand for future land use by interpolating the historical development trend. Based on QLB existing data, a land-use type transformation matrix is created over 1990-2015. We select 12 driving factors: elevation, slope, slope direction, distance from major highways, distance from Qinghai Lake, distance from the city center, distance from the township center, GDP density, population density, temperature, precipitation and a random factor representing unpredictable factors encountered in the process of land-use evolution. The latter may be related to different policies and disputes arising in the process of land expropriation, as formulated by decision-makers in response to the QLB changing political and economic conditions. The elevation, slope and slope direction factors are derived from DEM data. Distance is taken as the Euclidean distance to main roads, Qinghai Lake, and county and town centers. Population density data is obtained by using the area weight method of administrative units. Temperature and precipitation data are obtained from China's ground weather stations (http://data.cma.cn/).

\subsection{Methods}

\subsubsection{Land Development Scenarios}

Future land-use demand results from future land-use changes, and can be estimated by Markov chains, historic trend extrapolation, and economic models. In our model, land-use demand is inputted year by year, and is obtained through interpolation. Given future land demand in the QLB, the present land-use situation, and the goal of future ecological protection, three scenarios are developed for the QLB over 2020-2030: natural growth (NG), cropland protection (CP), and ecological protection (EP). 
The land-use dynamic change and the land-use conversion matrix methods were used to analyze land use demand. Land-use dynamics include the Single Land Use Dynamic Degree (SLUDD) [39], which reflects the rate of change $K$ in the quantity of land of a certain use type. The calculation formula is as follows:

$$
K=\frac{U_{b}-U_{a}}{U_{a}} \times \frac{1}{T} \times 100 \%
$$

where $U_{a}$ and $U_{b}$ represent the land-use area of a single land-use type at the beginning and the end of the study period. $T$ is the length of this period. If $K$ is greater than 0 , the study region is in land expansion period (otherwise, in land shrinkage). We use dynamic historical trends to deduce land demand in the future under the three scenarios.

Because QLB is not a complete administrative unit, its future land-use demand is difficult to predict. In view of this, the scenario analysis method is adopted. According to the characteristics of each scenario model and with reference to the Master Plan for Land Use of Qinghai Province and the Main Functional Zone Plan of Qinghai Province, the conversion probabilities of a Markov model are modified to estimate the demand area of each land type in each scenario. The specific scenarios are described below.

The NG scenario is set to be consistent with the historical land dynamics of the QLB. Under this scenario, we assume that land-use demand will not be affected by large-scale policy adjustments and will change according to the conversion probability matrix for the period 1990-2015. We assume that all land uses may convert into each other. With 10 years as the step size, a Markov model is used to predict the area of each land-use type under the NG scenario.

The CP scenario is set to be consistent with planning policy and to achieve its core goal of cropland protection. Under this scenario, the mutual interests of social, economic, and environmental protections are all considered. Under the premise of satisfying the QLB steady economic (GDP) growth, green mountains and green waters are protected, and basic cropland s (protected by national policies) are set as restricted areas. Basic cropland zoning cannot be converted into other land types. In this scenario, the expansion rate of construction land and the conversion rates of cropland to other lands are restrained to strengthen the protection of croplands. The conversion probability of cropland to construction land is reduced by $10 \%$, the conversion probabilities of croplands to woodlands, grasslands and water areas are reduced by $15 \%$, and the conversion probability of croplands to unused lands is reduced by $20 \%$.

The EP scenario is set to reflect ecological security, which has become very important in China. This scenario is to strengthen the protection of woodlands, grasslands, water areas and other ecological lands, while strengthening the conversion of other lands to ecological land. Under this scenario, the spatial distribution of land uses focuses on: (1) improving the regional ecological environment; (2) strictly protecting the ecological control area of Qinghai Lake; (3) strengthening the protection of wetlands, waters, and woodlands; and (4) strictly restricting wetlands. (Waters and wetlands are not changed into other land uses). The conversion probability from wetlands to grasslands decreases from $40.95 \%$ to $30.95 \%$. The conversion rate from croplands to woodlands increases from $0.02 \%$ to $5.02 \%$. The conversion rate from woodlands to grasslands decreases from $37.1 \%$ to $32.1 \%$. The conversion rate from unused lands to woodlands increases from $0.14 \%$ to $10.14 \%$. The conversion rate from grasslands to woodlands increases from $0.73 \%$ to $20.73 \%$.

\subsubsection{CA-Based FLUS Model}

We use the Future Land Use Simulation Model (FLUS), a CA model simulating land-use change and future land-use scenarios [40]. This model improves greatly over traditional CA models. The CA model is a dynamic model with discrete time, space and state [41], and is a powerful method for describing, recognizing and simulating the behavior of complex systems [42]. It includes four basic elements: cellular space, grid size, cell neighborhood and transition rule [43]. The cellular space represents the collection of all cells, each cell having its own attributes (such as land use/cover type, etc.), and the state of each cell in the next period is determined by the current state of the cell, the 
state of the cells in its neighborhood, and the transition rule. The CA transition principle is expressed as follows:

$$
S^{t+1}=\left(U^{d}, S^{t}, N^{t}, f\right)
$$

where $S^{t+1}$ represent the cellular state at time $t+1, d$ represents the number of land-cover states, $U^{d}$ represent the d-dimensional cellular space, $S^{t}$. represent the cellular state at time $t, N^{t}$ represent the state of neighbors at time $t$, and $f$. represent the transition rule [44].

In the FLUS model, the multi-layer artificial neural networks algorithm (ANN) is first used to obtain the suitability probabilities of various land types, based on land-use data and various driving factors (Table S3), including human activities and natural effects (terrain, traffic, location, policy, etc.). Next, a self-adaptive inertial competition mechanism based on roulette is used to solve the uncertainty and complexity of the interactive conversions of land-use types resulting from natural action and human activity. This progress gives the FLUS model a higher simulation accuracy, with better approximation of the actual land-use distribution.

ANN determines occurrence probabilities by uncovering the complex relationship between land-use patterns and various human and natural driving forces. ANN is a nonlinear and adaptive information processing model composed of a large number of processing units. Its advantage is that it can fit complex relationships between input data and training target through iterative learning [45]. The original land-use data is based on a $30 \mathrm{~m}$ resolution grid, and we resampled it into a $50 \mathrm{~m}$ resolution grid by using a bilinear interpolation method. The model can represent spatial interactions in the neighborhood, and fully integrate feedback among system elements through iteration and updating. Two main steps are addressed in this model: (1) The land cover changes over 1990-2015 provide key inputs to the ANN-CA (land cover type change rate, possibility of specific land cover change, and basic characteristics of patch size) to determine the demand for land use in the future; (2) A bottom-up spatial modeling component using CA. The ANN-CA model combines the strong ability of ANN to deal with non-linear relationships with the domain analysis function of the CA.

In the training stage, the ANN is trained by extracting the land-use classification data of the starting year, and the weight value of the network is obtained. In the prediction stage, the probabilistic values of land-use types that should be converted are obtained through ANN to determine whether a current cell can be converted. In the simulation process, ANN is responsible for providing the conversion rules of the geographic CA.

The sampling proportion for neural network training is $3 \%$ of the pixels, which were randomly selected across the QLB. All driving factors were normalized between 0 and 1 before training the network. The number of iterations for optimal accuracy was chosen through a trial and error process. As a rule of thumb, the number of hidden layers in the neural network is set to 12 . The error acceptance is within 0.01 and the iteration limit is 10,000 . The learning rate and terminal conditions of the ANN model are self-adaptive during the training process.

The ANN model network structure is divided into three layers. The first layer is the input layer, with a total of 19 neurons, 12 of which are factors of land-use change and 7 are types of land use in the neighborhood. The input layer formula is as follows:

$$
X=\left[x_{1}, x_{2}, \ldots, x_{n}\right]^{T}
$$

where $x_{i}$ represent the $i$ input neuron, one of the influencing factors (social economy and human activities). $X$ is the whole set of neurons.

The second hidden layer calculates the signal received by all input neurons on a cell at a certain moment according to the following formula:

$$
\text { net }_{j}(g, t)=\sum_{i} w_{i, j} \times x_{i}(g, t) .
$$


where $g$ is the simulation unit (cell) corresponding to the input signal, $t$ is the simulation time, $n^{2} t_{j}(g, t)$. is the signal received by neuron $j$ in the hidden layer, $w_{i, j}$. is the adaptive weight of neuron $i$ in the input layer and neuron $j$ in the hidden layer, which is modified in the training process.

The output layer is the third layer composed of seven neurons, corresponding to the probability values of the seven land-use types. The connection between the hidden layer and the output layer is determined by the sigmoid function:

$$
\operatorname{sigmoid}\left(\operatorname{net}_{j}(g, t)\right)=\frac{1}{1+e^{-n e t}(g, t)} .
$$

The probability of land-use type $k$ is calculated as follows:

$$
s g(g, k, t)=\sum_{n} w_{n, k} \times \operatorname{sigmoid}\left(n e t_{n}(g, t)\right)=\sum_{n} w_{n, k} \times \frac{1}{1+e^{-n e t_{n}(g, t)}}
$$

where $s g(g, k, t)$ represents the probability of occurrence of land-use type $k$ in grid cell $g$ at time $t$. Similar to $w_{i, j}, w_{n, k}$ is the adaptive weight between the hidden layer and the output layer. For each iteration time $t$ and grid cell $g$, the sum of the suitability probabilities of all land types is equal to 1 , with:

$$
\sum_{k} s g(g, k, t)=1
$$

The core of competition mechanism in the FLUS model is adaptive inertia, where the inertia coefficient of each land-use type is determined by the difference between amount of current land and land demand. An adaptive adjustment is carried out in an iterative process, so that the amounts of land converge to the predetermined targets. The adaptive inertia coefficient $A i_{k}^{\theta}$ of the land type $k$ at iteration time $t$ is:

$$
A i_{k}^{\theta}=\left\{\begin{array}{lll}
A i_{k}^{\theta-1} & \text { if } & \left|D_{k}^{\theta-2}\right| \leq\left|D_{k}^{\theta-1}\right| \\
A i_{k}^{\theta-1} \times \frac{D_{k}^{\theta-2}}{D_{k}^{t-1}} & \text { if } & 0>D_{k}^{\theta-2}>D_{k}^{\theta-1} \\
A i_{k}^{\theta-1} \times \frac{D_{k}^{\theta-1}}{D_{k}^{\theta-2}} & \text { if } & D_{k}^{\theta-1}>D_{k}^{\theta-2}>0
\end{array}\right.
$$

where $D_{k}^{\theta-1}$ and $D_{k}^{\theta-2}$ are the difference between the number of cells of land type $k$ and the demand for land $k$ at iterations $\theta-1$ and $\theta-2$, respectively. If the target land is inconsistent with the current land, the inertia coefficient is dynamically adjusted to conform to the changing trend in the next iteration. For example, when future development requires more cropland, but cropland actually decreases in the simulation, the inertia coefficient of cropland is increased to prevent the loss of cropland and to encourage the conversion of other lands to croplands.

The conversion matrix representing the possible land-use conversions under the different scenarios is presented in Figure 2.

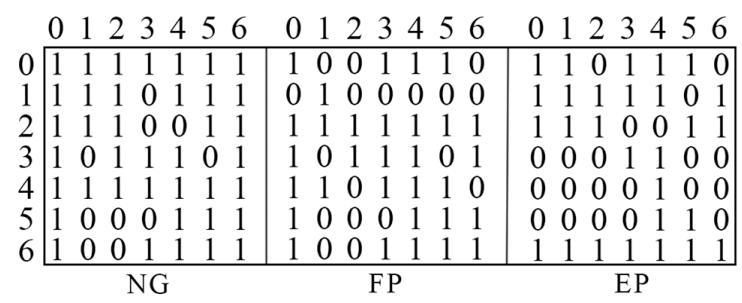

Figure 2. Rule matrix of land-use conversion under three scenario objectives in the Qinghai Lake Basin (outside frame: 0 grassland, 1 cropland, 2 construction land, 3 woodland, 4 wetland, 5 water, 6 unused land; inside frame, " 1 " indicates that land-use conversion is permitted; " 0 " means the opposite; Abbreviation: NG, Natural Growth scenario; CP, Cropland Protection scenario; EP, Ecological Protection scenario.). 
Conversion costs represent the difficulty of conversion from current land-use types to other land-use types and affect the dynamics of land-use change, as described below. After the probabilities of suitability of each cell are calculated by the ANN model, each type of land is allocated to each cell through CA model iterations. The probability $T p_{g k}^{t}$ of the transformation of cell $g$ into land-use type $k$ at time $t$ can be expressed as:

$$
T p_{g k}^{t}=s g(g, k, t) \times \Omega_{g, k}^{t} \times A i_{k}^{t} \times\left(1-s p_{p \rightarrow k}\right) .
$$

where $s p_{p \rightarrow k}$ is the normalized cost of converting land type $p$ into type $k$, and $1-s p_{p \rightarrow k}$ represents the difficulty of conversion. $\Omega_{g, k}^{t}$ represents the neighbors domain, with:

$$
\Omega_{g, k}^{t}=\frac{\sum_{N \times N} \operatorname{con}\left(p_{g}^{t-1}=k\right)}{N \times N-1} \times w_{k}
$$

where $\sum_{N \times N} \operatorname{con}\left(p_{g}^{t-1}=k\right)$ represents the total number of cells of land type $k$ after the last iteration time $t-1$ in the $N \times N$ Moore neighborhood; $w_{k}$ is the weight of land type $k$. In this study, a $3 \times 3$ field Moore window is used, and the number of CA iterations is set at 300 .

\subsubsection{Variable Importance Measures}

We use the random forest (RF) algorithm to evaluate which factors are dominant in the model. The measurements of the importance of spatial variables in ANN-CA models coincides with the identification of driving factors acting on land-use changes, and the RF algorithm can better accomplish this identification. The RF algorithm is a nonlinear modeling tool proposed by Breiman [40]. It measures the importance of each factor. The Bootstrap resampling method (a sampling algorithm with fallback) is used to extract multiple samples from the original sample, and each Bootstrap sample is modeled as a decision tree. Then RF combines the predictions of these multiple decision trees and generates the final prediction by voting [41].

\subsubsection{Estimation of Carbon Storage based on the InVEST Model}

The InVEST model requires fewer input parameters and is used to evaluate carbon storage. We combine the ANN-CA model with the InVEST model, which simulates the impact of land-use changes on carbon reserves in the QLB over 2020-2030, based on the three scenarios. The general modeling framework is divided into two parts (Figure 3): (1) historical regional land-use data and the CA model for the determination of future land-use change, and (2) the InVEST model to evaluate potential regional carbon reserves. A more detailed description can be found in the InVEST 3.2.0 User's Guide [21] and in Supplementary Materials.

The ecosystem carbon pool consists of four parts (Figure 3): above-ground biocarbon, under-ground biocarbon, soil carbon, and dead organic carbon. The carbon storage of above-ground biomass mainly includes the carbon content of vegetation, tree trunks, branches, leaves, etc. Underground biological carbon is mainly the carbon content in roots of active vegetation. Soil carbon is generally limited to the carbon content in mineral soil, but also includes organic soil. Dead organic carbon includes litter or the carbon content of dead trees. The InVEST model assumes that each land cover is characterized by a total carbon density, which aggregates above-ground, below-ground, soil organic and dead organic matter carbon densities.

The model considers that a change in carbon storage results from a land-use change, thus simplifying the carbon cycle process. The model is [21]:

$$
C_{i}=C_{i 1}+C_{i 2}+C_{i 3}+C_{i 4}
$$


where $i$ represents the land-use type, $C_{i}$ represent the total carbon density of land-use type $i(\mathrm{Mg} / \mathrm{ha})$ $\left(\mathrm{Mg}\right.$, Megagram: a unit of mass equal to $10^{6} \mathrm{~g}$ ), $C_{i 1}$ the above-ground density, $C_{i 2}$ represent the underground density, $C_{i 3}$ the soil carbon density, and $C_{i 4}$ the dead organic carbon density.

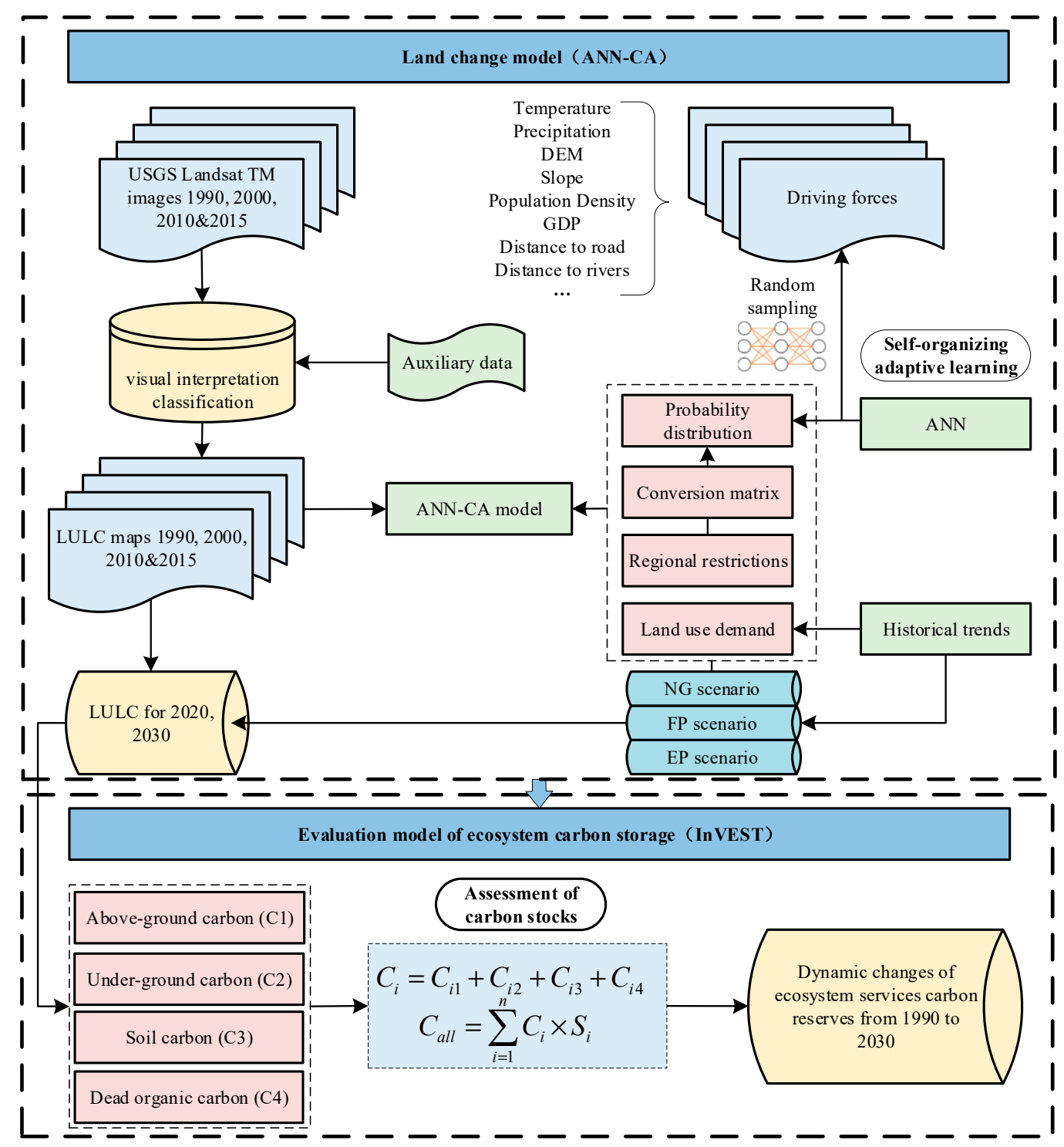

Figure 3. General modeling framework for the integrated Artificial Neural Networks-Cellular Automata and InVEST models (LULC, land use and land cover; NG, Natural Growth scenario; CP, Cropland Protection scenario; EP, ecological protection scenario; See Supplementary Materials for additional information on the model).

Total carbon storage is computed as follows:

$$
C_{\text {all }}=\sum_{i=1}^{n} C_{i} \times S_{i}
$$

Equation (12) accounts for the area of land-use $i\left(S_{i}\right.$, ha), the numbers of land-use types $(n)$, and the total carbon storage $\left(C_{\text {all }}, \mathrm{Mg}\right)$ [21]. We run the InVEST model by inputting carbon densities. The results are then loaded into ArcGIS 10.3 to analyze the spatial distribution of carbon storage in the QLB (See Supplementary Materials for additional information). Based on research by Li et al. [46], 
Xie et al. [47,48], and Huang et al. [49], the carbon density in different LULC ecosystems is presented in Table 1.

Table 1. Carbon density for different LULC types in the QLB (Mg/ha).

\begin{tabular}{cccccc}
\hline LULC & $\begin{array}{c}\text { Above } \\
\text { Ground }\end{array}$ & $\begin{array}{c}\text { Below } \\
\text { Ground }\end{array}$ & $\begin{array}{c}\text { Soil } \\
\text { Organic }\end{array}$ & $\begin{array}{c}\text { Dead } \\
\text { Organic }\end{array}$ & Source \\
\hline Grassland & 35.3 & 26.5 & 80.9 & 2.2 & {$[48-50]$} \\
Cropland & 5.7 & 80.7 & 28.4 & 1 & {$[48-50]$} \\
Construction & 12 & 0 & 71 & 1 & {$[48-50]$} \\
Land & 42.4 & 120 & 236.9 & 67.5 & {$[48-50]$} \\
Woodland & 35 & 90 & 208.5 & 25 & {$[48-50]$} \\
Wetland & 10 & 8 & 0 & 0 & {$[48-50]$} \\
Water & 4 & 20 & 74.6 & 0 & {$[48-50]$} \\
Unused Land & 4 & & & \\
\hline
\end{tabular}

\section{Results}

\subsection{Importance of Driving Factors for each LUC Type in the Model}

The Random Forest algorithm provides the importance of each driving factor for each land use, as presented in Figure 4. The main driving factors of grassland change are temperature, precipitation and elevation. The driving factor influencing the change in croplands is the distance between cells and main roads. Specifically, the loss of croplands is mainly due to transport accessibility and population growth and transfer, resulting in urban expansion and agricultural restructuring. The intensive use of urban and other non-agricultural lands slows down the loss of croplands. The distances to the town center and the main highway are the driving factors that influence construction land change. The driving factors for woodland growth include elevation and temperature. Elevation is the main driving factor of wetland change. Distance and elevation from Qinghai Lake are the main driving factors for structural changes in water area. The closer the area is to Qinghai Lake and the lower the elevation, the easier it is for other types of land to be converted into water. The elevation is the main driver of unused lands change. In summary, the dominant driving factors of land-use change in the QLB are altitude, distance to main roads, and temperature.

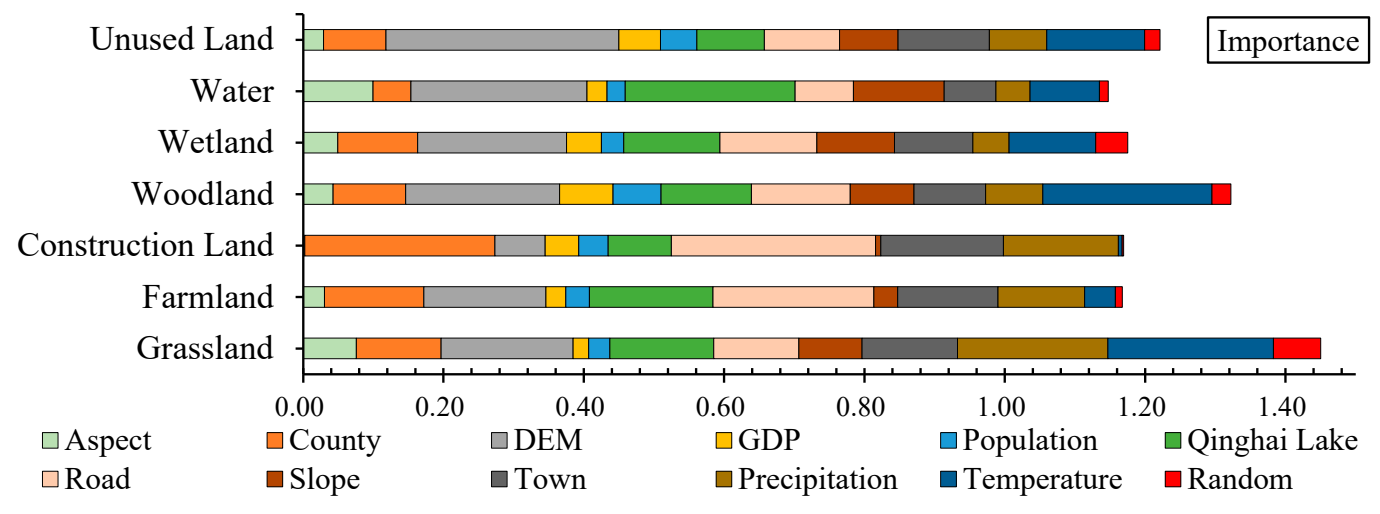

Figure 4. The importance of factors for each type of land use in the Random Forest model (implemented on the Python platform). The numbers represent the contribution degree. The greater the number, the greater the contribution of the driving factor to the land-use change.

\subsection{Simulation Model Validation}

There are two commonly-used methods to test model results: point-by-point comparison and overall comparison. The point-by-point method uses the Kappa accuracy coefficient, and the results are presented in Table S1 in Supplementary Materials. 
Based on the land-use map in 2010 and corresponding driving factors, the land-use scenario for 2015 is simulated, and compared with the actual 2015 land-use map. The simulation accuracy is $92.4 \%$, and the Kappa coefficient is 0.86, indicating a high accuracy (Table S1). Overall, the simulated land use in 2015 is consistent with the actual land use. In terms of the simulation accuracy for various land uses, water areas have the highest accuracy, with Kappa $=0.99$. Kappa $=0.97$ for unused lands. However, the accuracy for construction lands is relatively poor, with Kappa $=0.68$. Croplands, woodlands, and wetlands have also high accuracies. The main reasons for the high accuracy for water areas is that they are mainly composed of large water surfaces, such as the Qinghai Lake and the Shaliu and Buha rivers, which have been classified as important ecological protection areas and have been relatively stable over time.

\subsection{Land Use and Land Cover Change over 1990-2030}

LULC maps were generated and displayed using Landsat TM images from 1990 to 2015. The four reclassified land-use maps have a uniform spatial resolution of $50 \mathrm{~m} \times 50 \mathrm{~m}$ (Figure 5). The overall classification accuracy is $83.5 \%$ and Kappa is higher than 0.80 , which meets the standards of this study. Land changes in the QLB from 1990 to 2015 are as follows: construction lands increased sharply to 5131 ha (+592\%); wetlands decreased to 109,428 ha $(-8.64 \%)$; croplands decreased to 52,316 ha $(-3.81 \%)$; woodlands increased to 56,315 ha (+23.83\%); grasslands increased to 2,050,812 ha (+0.75\%); and unused lands decreased to 191,742 ha $(-10.17 \%)$.

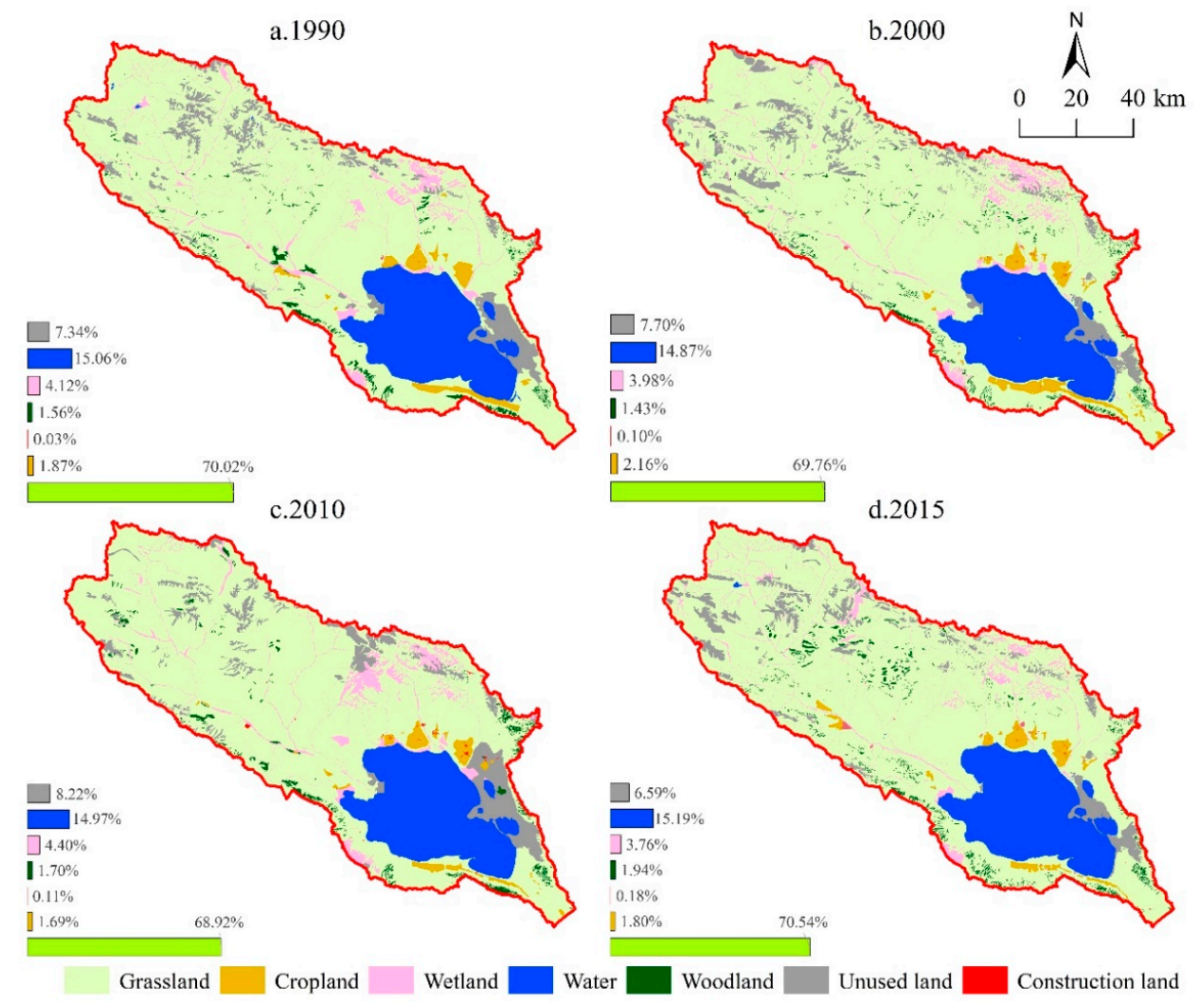

Figure 5. Land-use maps in the Qinghai Lake Basin over 1990-2015. These maps were interpreted from Landsat TM 5 and 7 satellite images (http://earthexplorer.usgs.gov).

Table 2 shows the transitions of the seven LUC types from 1990 to 2015 . For a more detail about LUC inflow and outflow, see Figure S2. Grasslands, construction lands, woodlands and water areas increased, while croplands, wetlands, and unused lands decreased. According to previous studies [51], the water area of Qinghai Lake decreased from 1987 to 2005, and precipitations increased slightly. Then, rapid increases in the QLB were observed from 2005 to 2016, which is similar to our findings (Table S2). 
Table 2. Land use/cover conversion matrix from 1990 to 2015 in the Qinghai Lake Basin (Unit: ha).

\begin{tabular}{|c|c|c|c|c|c|c|c|c|}
\hline & Grassland & Cropland & Construction Land & Woodland & Wetland & Water & Unused Land & Total \\
\hline \multirow{2}{*}{ Grassland } & $1,865,864$ & 14,659 & 3271 & 42,263 & 48,525 & 2335 & 60,820 & \multirow{2}{*}{$2,037,736$} \\
\hline & $91.57 \%$ & $0.72 \%$ & $0.16 \%$ & $2.08 \%$ & $2.38 \%$ & $0.11 \%$ & $2.99 \%$ & \\
\hline \multirow{2}{*}{ Cropland } & 15,028 & 37,324 & 1288 & 0 & 73 & 238 & 439 & \multirow{2}{*}{54,390} \\
\hline & $27.63 \%$ & $68.62 \%$ & $2.37 \%$ & 0 & $0.13 \%$ & $0.44 \%$ & $0.81 \%$ & \\
\hline \multirow[b]{2}{*}{ Construction Land } & 113 & 203 & 425 & 0 & 0 & 0 & 0 & \multirow[b]{2}{*}{741} \\
\hline & $15.28 \%$ & $27.39 \%$ & $57.34 \%$ & 0 & 0 & 0 & 0 & \\
\hline \multirow{2}{*}{ Woodland } & 30,572 & 0 & 0.50 & 13,710 & 782 & 49 & 365 & \multirow{2}{*}{45,479} \\
\hline & $67.22 \%$ & 0 & 0 & $30.15 \%$ & $1.72 \%$ & $0.11 \%$ & $0.80 \%$ & \\
\hline \multirow{2}{*}{ Wetland } & 58,753 & 130 & 146 & 106 & 58,964 & 1063 & 623 & \multirow{2}{*}{119,785} \\
\hline & $49.05 \%$ & $0.11 \%$ & $0.12 \%$ & $0.09 \%$ & $49.22 \%$ & $0.89 \%$ & $0.52 \%$ & \\
\hline \multirow{2}{*}{ Water } & 3292 & 0.50 & 0 & 0 & 708 & 433,238 & 512 & \multirow{2}{*}{437,750} \\
\hline & $0.75 \%$ & 0 & 0 & 0 & $0.16 \%$ & $98.97 \%$ & $0.12 \%$ & \\
\hline \multirow{2}{*}{ Unused Land } & 79,321 & 0 & 0 & 236 & 378 & 4561 & 131,958 & \multirow{2}{*}{213,453} \\
\hline & $37.16 \%$ & 0 & 0 & 0 & $0.18 \%$ & $2.14 \%$ & $60.42 \%$ & \\
\hline Total & $2,050,812$ & 52,317 & 5131 & 56,316 & 109,428 & 441,483 & 191,717 & $2,912,334$ \\
\hline
\end{tabular}


Figure 4 shows that the increases in construction lands and woodlands are mainly due to increased use of resources for human activities and infrastructure construction, occupying large amounts of unused lands and grasslands. In developing countries, human activities, such as overgrazing, contribute to the degradation of nearly $90 \%$ of grasslands [52]. Governments often choose economic benefits at the expense of the environment. Then, changes in grasslands bring great pressure on livestock production. Woodlands increased from 1.56\% in 1990 to $1.94 \%$ in 2015, mainly because of the implementation of the Three-North Shelterbelt System Construction Project in 1978, the strengthening of ecological construction by the Qinghai Government, the overall continuous reversal of desertification in the QLB, and the artificial afforestation of 889.5 million ha over the last 40 years [53]. The QLB has emphasized increased grain production capacity and continuous reclamation of new grasslands, with construction lands increasing from $0.01 \%$ to $0.18 \%$ and occupying mainly croplands and grasslands. Unused lands have been greatly reduced, from 7.34\% in 1990 to $6.60 \%$ in 2015; wetlands have also been reduced, from $4.13 \%$ to $3.77 \%$. Previous studies [54] show that degraded grasslands accounted for $65 \%$ of the land cover over 2006-2010, and were mainly located in the north and surrounding the QLB, which is consistent with our findings. From 1990 to 2015, the area of unused lands converted into grasslands in the QLB was the largest (79,321 ha), indicating that primarily because of increased human population and activities. Second, grasslands were converted into 60,820 ha of unused lands. Almost all these grasslands had been degraded. After years of glacial snow melting, some of the degraded grasslands have been transformed into wetlands, while others have become unused bare lands, greatly aggravating desertification. Regional animal husbandry has a good economic foundation and has displayed rapid development and a large demand for grassland resources. At the same time, there is wetlands degradation caused by overgrazing. Wetlands have been transformed into $596 \mathrm{~km}^{2}$ of grasslands. The sharp decrease in wetland areas is due to the reduction in inland beaches and swamplands caused by melting alpine ice and snow. More importantly, because of increased population and activities, many wetlands have been developed into pasture. With rapid economic development, construction lands are also expanding rapidly and are mainly located in tourism areas around Qinghai Lake and prefecture residences.

Figure 6 presents the simulated land-use maps for 2020 and 2030 under the three scenarios. By comparing Figures 5 and 6, we can see future trends of land-use conversion under the NG scenario: croplands, woodlands, wetlands, and water areas decline over 2015-2030, land desertification intensifies, and the ecological environment of the QLB further deteriorates. To analyze future land-use changes in the QLB, the projected land-use areas in 2020 and 2030 are presented in Table 3.

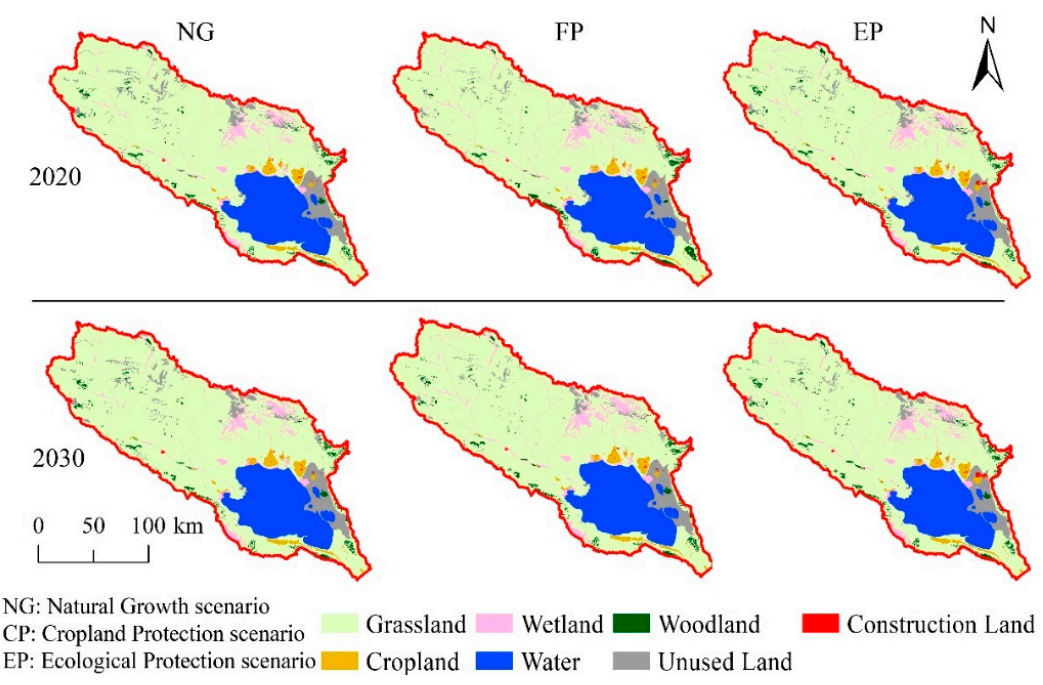

Figure 6. Land-use simulation map under NG, CP and EP scenarios in the QLB over 2020-2030. The map for 2020-2030 was simulated using ANN-CA model. 
By 2020, under the CP scenario, croplands, construction lands, water areas and unused lands will have declined by $3.68 \%, 9.27 \%, 0.26 \%$, and $7.44 \%$ respectively, as compared to 2015 . Wetlands will have increased the most (13.71\%), followed by woodlands (5\%). Under the CP scenario, wetlands will be effectively protected, increasing by $16.87 \%$, and the rate of cropland loss will also have been slowed. By 2030, under the CP scenario, croplands and unused lands will have declined by $1.4 \%$ and $16.05 \%$, respectively, compared to 2015. Construction lands, woodlands, and wetlands will have increased by $15 \%, 10 \%$, and 15\%, respectively. Under the EP scenario, construction lands will be reduced by $41.87 \%$, and be almost the same as in 2020 . Wetlands will be effectively protected, increasing by $22.72 \%$, as compared to 2015. This scenario is of great significance for maintaining and improving the ecological environment of the QLB.

Table 3. Changes in land use/cover in the Qinghai Lake Basin over 2020-2030 under the three scenarios (Unit: $\mathrm{km}^{2}$ ).

\begin{tabular}{cccccccc}
\hline \multirow{2}{*}{ Land Type } & \multirow{2}{*}{$\mathbf{2 0 1 5}$} & \multicolumn{3}{c}{$\mathbf{2 0 2 0}$} & \multicolumn{3}{c}{$\mathbf{2 0 3 0}$} \\
\cline { 3 - 7 } & & NG & $\mathbf{C P}$ & $\mathbf{E P}$ & $\mathbf{N G}$ & $\mathbf{C P}$ & $\mathbf{E P}$ \\
\hline Grassland & 20,508 & 20,539 & 20,508 & 20,539 & 20,599 & 20,599 & 20,713 \\
Cropland & 523 & 495 & 504 & 492 & 502 & 516 & 492 \\
Construction land & 51 & 31 & 47 & 30 & 31 & 59 & 30 \\
Woodland & 563 & 560 & 591 & 619 & 573 & 619 & 562 \\
Wetland & 1094 & 1074 & 1244 & 1279 & 1032 & 1258 & 1343 \\
Water & 4415 & 4391 & 4403 & 4415 & 4395 & 4411 & 4394 \\
Unused land & 1917 & 1984 & 1775 & 1698 & 1940 & 1610 & 1538 \\
\hline
\end{tabular}

\subsection{Temporal Patterns of Carbon Storage}

\subsubsection{Total Carbon storage and Potential Regional Carbon Losses}

Figure 7 shows that the total carbon reserves of the QLB in 1990, 2000, 2010, 2015 were 394, 392, 396, and 396 Tg C, respectively. Carbon reserves decreased over 1990-2000, indicating that the land carbon sequestration capacity weakened. Carbon sequestration capacity rose sharply over 2005-2010, due to the acceleration of the Three-North Shelterbelt project, with systematic woodland protection by the local government.

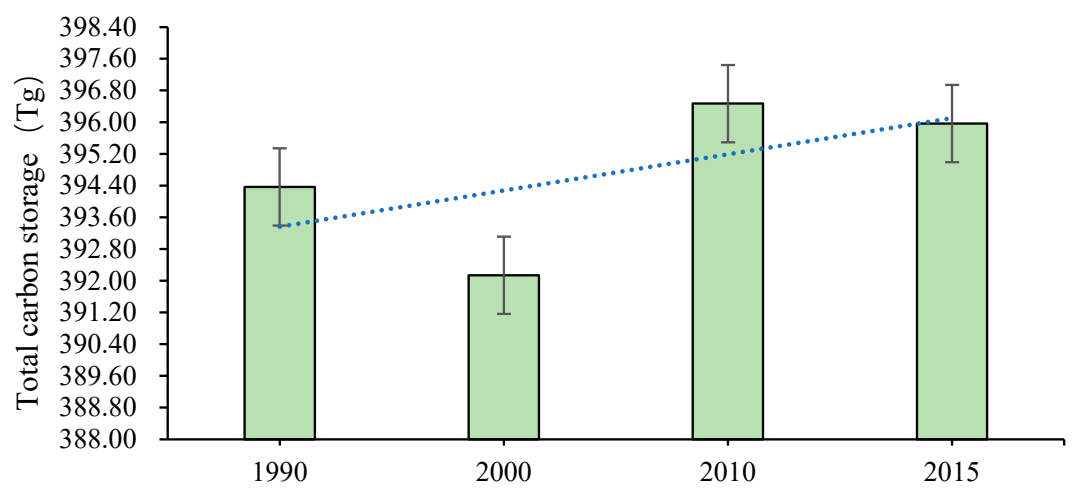

Figure 7. Total carbon storage over 1990-2015 in the QLB (calculation based on Equations (11) and (12).

The rapid growth of woodlands over 2010-2015 and the improvement of the ecological environment increased carbon storage; however, total carbon storage decreased slightly, mainly because wetlands decreased during this period. The area of wetlands is affected by the melting of mountain ice and snow, which reduces the area of inland beaches and marshes. Also, more importantly, a large number of wetlands have been developed into grasslands because of the increase in population and human activities. 
Carbon storage changes corresponding to the various land uses over 2015-2030 are illustrated in Figure 8. In the NG scenario, the loss of carbon sequestration in wetlands is the largest $(2.23 \mathrm{Tg} \mathrm{C})$, followed by croplands $(0.24 \mathrm{Tg} \mathrm{C})$. Increased carbon sequestration takes place in grasslands, woodlands and unused lands, with the largest increase in grasslands (1.32 Tg C). In the CP scenario, carbon sequestration increases for wetlands $(5.88 \mathrm{Tg} \mathrm{C})$, followed by woodlands ( $2.63 \mathrm{Tg} \mathrm{C})$. Carbon sequestration in unused lands and water areas decreases, particularly in unused lands (3.04 $\mathrm{Tg} \mathrm{C})$. Under the EP scenario, carbon sequestration increases in wetlands ( $8.91 \mathrm{Tg} \mathrm{C})$, followed by woodlands and grasslands (2.97 Tg C). Croplands, unused lands, and construction lands gradually lose carbon storage, particularly unused lands (49.61\% of the total QLB carbon storage).

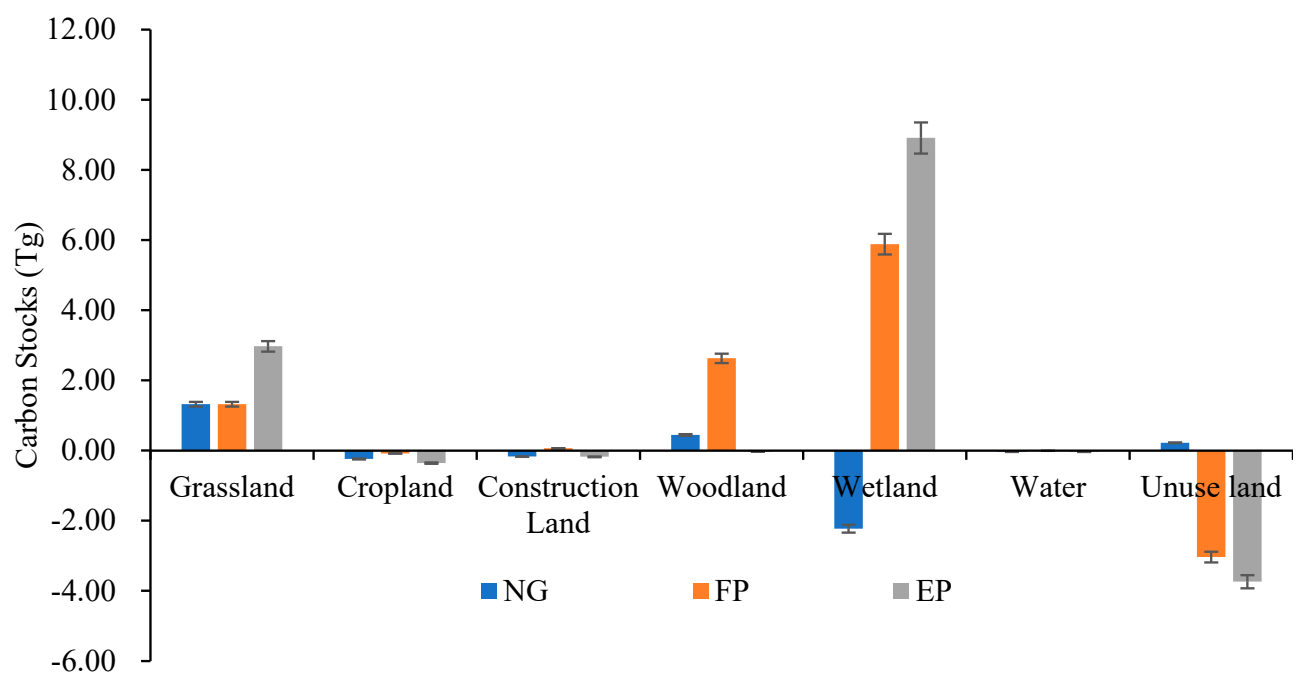

Figure 8. Sequestered carbon content of different land uses over 2015-2030 under different scenarios.

Table 4 shows that grassland have the largest carbon reserves, followed by wetlands, woodlands, unused lands, water areas and croplands. Construction lands and croplands have the smallest carbon reserves.

Table 4. Carbon reserves of different land types in the QLB over 2015-2030 (Unit: Tg).

\begin{tabular}{cccccccccc}
\hline Carbon Storage & Grassland & Cropland & $\begin{array}{c}\text { Construction } \\
\text { Land }\end{array}$ & Woodland & Wetland & Water & $\begin{array}{c}\text { Unused } \\
\text { Land }\end{array}$ & Total \\
\hline \multicolumn{2}{c}{2015} & 297.16 & 6.01 & 0.43 & 26.29 & 39.23 & 7.95 & 18.91 & 395.97 \\
\hline \multirow{2}{*}{2020} & NG & 297.60 & 5.68 & 0.25 & 26.15 & 38.49 & 7.90 & 19.56 & 395.64 \\
& CP & 297.16 & 5.79 & 0.39 & 27.60 & 44.61 & 7.93 & 17.50 & 400.97 \\
& EP & 297.60 & 5.65 & 0.25 & 28.92 & 45.85 & 7.95 & 16.75 & 402.96 \\
\hline \multirow{2}{*}{2030} & NG & 298.48 & 5.76 & 0.26 & 26.73 & 37.00 & 7.91 & 19.13 & 395.28 \\
& CP & 298.48 & 5.92 & 0.49 & 28.92 & 45.11 & 7.94 & 15.87 & 402.74 \\
& EP & 300.13 & 5.65 & 0.25 & 26.25 & 48.14 & 7.91 & 15.17 & 403.50 \\
\hline
\end{tabular}

In the NG scenario, grassland carbon storage in 2020 increases slightly over 2015 (0.44 Tg C). Unused land carbon storage increases by $0.65 \mathrm{Tg} C$, and carbon storage of wetlands, croplands, and woodlands decreases over 2015-2020 by $0.74 \mathrm{Tg}$ C, $0.33 \mathrm{Tg}$ C, and $0.13 \mathrm{Tg}$ C, respectively. By 2030, the carbon storage of grasslands and woodlands will have increased by $1.32 \mathrm{TgC}$ and $0.44 \mathrm{Tg} \mathrm{C}$, respectively, while the carbon storage of croplands, construction lands, and wetlands will have decreased by $4.02 \%$, $39.65 \%$, and $5.68 \%$, respectively, as compared to 2015 . Therefore, if the area develops according to the NG scenario, important carbon reserves in croplands and wetlands will have been reduced, seriously affecting the QLB balance of carbon reserves.

The CP scenario accounts for land demand for development, but also pays attention to cropland protection and considers the impact of cropland policies on ecosystems, with economic growth relying 
mainly on tourism. Grassland carbon storage remains unchanged in 2020, woodland and wetland carbon storage increases by $1.31 \mathrm{Tg} \mathrm{C}$ and $5.38 \mathrm{Tg} \mathrm{C}$, respectively, while construction land carbon storage decreases slightly. Carbon storage in grasslands, woodlands and wetlands remain unchanged over 2020-2030, while carbon storage of unused lands and croplands decreases. The growth rate of construction lands is reduced, croplands are effectively protected, and carbon reserves in woodlands and wetlands is reduced, which are all conducive to a balance of carbon reserves in the QLB.

In the EP scenario, the ecological situation of the QLB improves significantly. By 2020, carbon storage increases by $0.44 \mathrm{Tg} C$ for grasslands, by $2.63 \mathrm{Tg} C$ and $6.62 \mathrm{Tg} C$ for woodlands and wetlands respectively, and decreases by $0.36 \mathrm{Tg} C$ and $2.16 \mathrm{Tg} C$ for croplands and unused lands respectively. The increase in carbon reserves in woodlands is enough to offset the corresponding decrease in unused lands. Compared with 2015, total carbon storage in the whole study area increases by $7.5 \operatorname{Tg} C$ in 2030 . Most of the increased carbon storage is due to wetlands. Carbon storage in grasslands and wetlands increases by $1 \%$ and $22.72 \%$, respectively, over 2015-2030, while carbon storage in croplands and unused lands decreases by $5.93 \%$ and $19.78 \%$, respectively. This scenario promotes the protection and survival of local species, and contributes to the coordination of carbon balance with economic development.

\subsubsection{Spatial patters of Future Carbon Storage}

Figure 9 presents the spatial distribution of carbon storage in the QLB over 1990-2030. Overall, Qinghai Lake has the lowest carbon storage, with an average carbon density of $0-20 \mathrm{Mg} / \mathrm{ha}$. Over 1990-2015, grasslands account for at least $68.91 \%$ of the total area, with a carbon storage density of $144.9 \mathrm{Mg} / \mathrm{ha}$, and the largest carbon storage. Carbon storage in northern Qinghai Province is relatively high, due to large-scale woodlands, which sequester a lot of carbon in the Tianjun Mountain in Haiyan and Tianjun counties. The above-ground and underground biomass carbon content of reeds and other plants growing in wetlands is relatively high, and their carbon sequestration ability is strong. The average carbon storage density in eastern Qinghai Lake lies in the $100-120 \mathrm{Mg} / \mathrm{ha}$ range. A more detailed spatial analysis of carbon storage in QLB sensible areas is presented in Supplementary Materials (Figures S3 and S4).
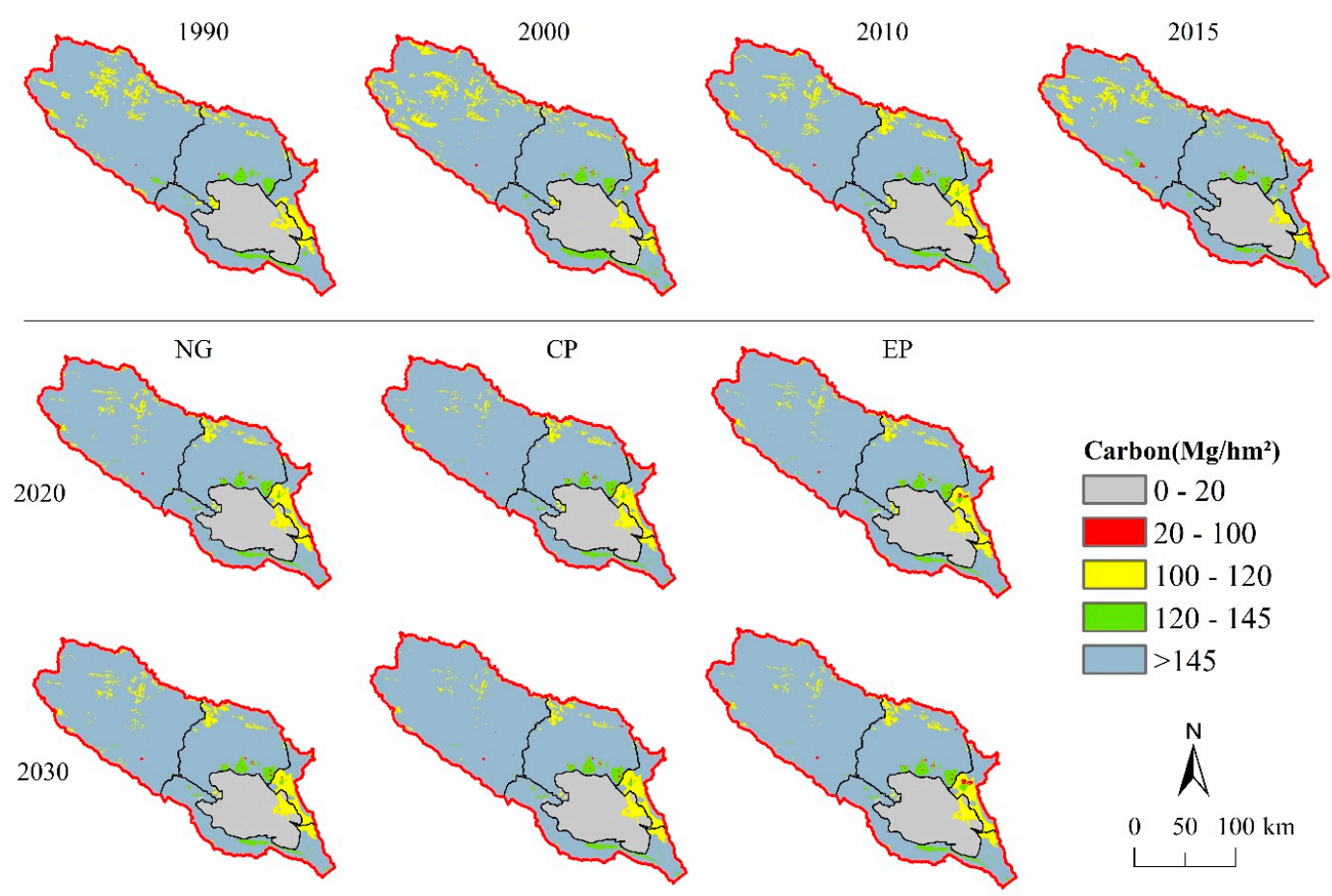

Figure 9. Spatiotemporal variations of carbon storage in the QLB:1990-2030. 


\section{Discussion}

\subsection{Analysis of Land Use and Cover Change}

Table 3 shows that $37.16 \%$ of unused lands was converted to grasslands, and $49.05 \%$ of wetlands was converted to grasslands from 1990 to 2015. How did this large conversion from unused lands to grasslands happen? Unused lands underwent reclamation to satisfy the increasing demand for grazing by sheep and yaks in some towns, and also because of grasslands degradation due to heavy grazing in the original grasslands and, after a few years, in newly reclaimed areas. The shift between grasslands and wetlands was caused by a governmental ecological restoration project and more rainfall in recent years. Conversion of wetlands to grasslands was also caused by excess irrigation for croplands and soil erosion. Also, grasslands may have continued to degrade into barren lands. We see a slight decrease of wetlands in some towns and in the whole study area. In the short term (1990-2015), wetlands decreased slightly due to reduced rainfall over this period in the QTP's climate cycle. However, in the next climate cycle period, rainfall will be reduced again, and the climate will be warmer. The newly gained wetlands and woodlands may disappear, and newly reclaimed grasslands will degrade more quickly. In addition, there will be more people and livestock. Human land-use activities have already rendered the land more fragile and sensitive to climate change. Thus, the current land-use system is unsustainable in the long term. The phenomena that occurred in the study area comprise a snapshot of the QTP's land system. If the same process that occurred in the QLB happens across the entire QTP, the ecological security of China and even Asia might be threatened.

\subsection{Measurement of Carbon Storage in the QLB}

This paper has revealed historical spatial changes in carbon storage in the QLB. It has also simulated future changes in carbon storage in the area. As expected, woodlands and grasslands accumulate more carbon storage than croplands and water areas. From 1990 to 2015, 67.47\% of woodlands were converted into grasslands, with a greater impact because grazing negatively impacts carbon storage on the ground. Studies from India have also shown that when natural woodlands are converted into grasslands, soil organic carbon stocks decrease by $23 \%$. Current studies show that, under the EP scenario, the QLB ecological situation will improve significantly. Carbon storage of grasslands and croplands will decrease continuously until 2030, but increased carbon storage by woodlands will compensate for this decrease. Fang et al. [14] believe that the continuation of national afforestation and reforestation projects may significantly contribute to global terrestrial carbon sequestration. According to our model, important carbon reserves in woodlands, grasslands, and wetlands will increase. Although grassland carbon reserves remain unchanged as compared with natural growth scenarios, increased wetlands have an important role in promoting the protection and survival of local species. They also contributes to the coordination of economic development and carbon balance. Quantifying the dynamics of carbon storage in the QLB ecosystem is very important for understanding changes in carbon storage in the whole ecosystem of the QTP.

There have been many studies on ecosystems in the QTP, but few studies on carbon storage of single ecosystems. QLB is an important ecological security barrier and an ecologically fragile area in Western China. Changes in carbon storage in this ecosystem have not only an important impact on the region's ecological quality, but also a close relationship with local climate conditions and the ecological security in China's western region. Analysis of such changes is important to ensure regional ecological security and to promote the coordinated development of the regional society, economy and ecology. This study also shows that ecosystems with large carbon reserves may not exhibit high carbon sequestration, which is consistent with the result of an earlier study [55]. Studying the supply and demand of carbon storage and storage services in the QLB, so as to mitigate climate change in the QTP's ecological environment, reducing the emission level of carbon, and improving storage capacity, are all essential measures for improving global ecological services in sensitive areas. 


\subsection{Generality of Models}

LUCC and the resulting changes in ecosystem services have become a research hotspot, and some studies have attempted to evaluate the potential impacts of LUCC on ecosystem services [56-58]. Future ecosystem services have been assessed by using two models. The ANN-CA model was used to forecast LUCC under different scenarios. The InVEST model was adopted to calculate changes in carbon storage due to LUCC. Combining the land-use change model and the InVEST model to optimize the simulation of land-use changes has become an increasingly important research focus and direction. For example, He et al. [59] assess the potential impact of urban expansion on regional carbon storage by linking the LUSD-urban and InVEST models. The relative error between simulated carbon storage losses and actual losses is less than $12 \%$. Effective progress has been made in this study, which uses the ANN-CA model to optimize the quantity and spatial allocation of land use in the QLB, with good simulation results (Table S1). The model integrates macro-driving factors and micro-pattern land-use change; it also considers four factor categories: topographic, socio-economic, administrative center, and traffic. Although the model can effectively simulate the impact of future land-use changes on carbon storage in a relatively short time, there are limitations in the long-term. It is expected that the climate around the QLB will become warmer and wetter, which will lead to changes in vegetation pattern and soil carbon density. When models are used for long-term predictions, the effects of climate change cannot be ignored. Finally, $99.82 \%$ of the study area is uninhabited and largely covered by vegetation, which is driven by climate and environmental factors. Incorporating these factors into LUCC simulation remains a challenge.

\subsection{Limitations and Future Research}

Based on the research of Li et al. [60] and Xie et al. [47], carbon density parameters for different carbon sources can only roughly estimate the carbon storage of a regional ecosystem and its socioeconomic value. Although the accuracy of these estimate must be further improved, this does not affect the overall research results of this paper, which could support decision-making in the region's relevant government departments. Future studies will collect more detailed data on soil and vegetation carbon density, in turn facilitating further research. However, this study still has some deficiencies. For example, a limitation of the InVEST model is its inability to estimate carbon storage in water and the carbon density of unused lands. In the InVEST model, regional carbon storage is calculated as the sum of the above-ground, under-ground, soil organic matter and dead organic matter carbon. The variation of carbon density within each land use type and seasonal variations in carbon loss among LUC types were not accounted for. Another shortcoming of this study is the land cover classification. The original spatial resolution of the data is $30 \mathrm{~m} * 30 \mathrm{~m}$. To ensure data uniformity, all spatial data were resampled uniformly to a $50 \mathrm{~m} * 50 \mathrm{~m}$ grid, and this might have led to reallocation errors. For future research, it is necessary to better describe land cover patterns and obtain more accurate carbon storage values.

\section{Conclusions}

In this study, we have used the InVEST and ANN-CA models to analyze and simulate the temporal and spatial changes in ecosystem carbon storage due to land-use changes in the QLB in the northeastern QTP over 1990-2030 under three scenarios. The amount of and spatial differences in carbon storage in the QLB were discussed, and the following are the main conclusions: (1) Using the ANN-CA model with the InVEST model can effectively assess the potential impact of carbon storage in sensitive areas under future ecological constraints. (2) Dependence on the animal husbandry industry in the QLB leads to overgrazing. From 2010 to 2015, the QLB carbon storage ecosystem has displayed a downward trend, due mainly to decreased grasslands and wetlands. (3) Under the CP scenario, the carbon storage ecosystem displays a downward trend. (4) Under the EP scenario, focusing on important carbon sources such as ecological control areas, woodlands and wetlands, the role of land in 
enhancing the carbon sequestration potential is strong. To a certain extent, land use in the QLB has been optimized, and life, production and ecology have been improved. The spatial structure has a profound influence on promoting the orderly development of the QLB economy, society, and ecology. This study has found that the establishment of high-quality cultivated pasture is an important measure to improve carbon storage [23]. In the long run, the reclamation of high-quality cultivated pasture may not only provide livestock with high-quality pasture and reduce pressure on natural grasslands, but also ensure normal improvement or restoration of natural grasslands and wetlands. In the future, government should continuously optimize the land-use structure and spatial distribution based on a strict implementation of overall land-use planning. This would include changing trends toward a single grassland type, restricting development of inland beaches, protecting important wetland and woodland resources, and adopting a variety of bioengineering measures to prevent soil erosion and soil desertification. The government should establish reasonable ecological compensations to farmers and herdsmen for protecting the ecological environment and promoting its healthy development.

Supplementary Materials: The following are available online at http://www.mdpi.com/2072-4292/12/3/528/s1, Figure S1: Verification points for the visual interpretation of remote sensing classification, Figure S2: Land-use conversions over 1990-2015, Figure S3: Carbon sequestration of different land types under three scenarios over 2015-2030 in the Qinghai Lake Basin, Figure S4: Loss of carbon sequestration in different land types under three scenarios over 2015-2030 in the Qinghai Lake Basin sensitive areas. Table S1: Simulation results: percentage accuracy and Kappa coefficient, Table S2: Summary of land use/cover areas over 1990-2030 (Unit: ha), Table S3: Data parameters for the land-use change model.

Author Contributions: Conceptualization, J.L. and J.G.; methodology, J.L., S.L. and J.Z.; validation, J.L., J.G., and J.-M.G.; data curation, J.L. and J.G.; writing—original draft preparation, J.L.; writing-review and editing, J.L. and J.-M.G.; funding acquisition, J.G. and S.L. All authors have read and agreed to the published version of the manuscript.

Funding: This research was funded by the National Natural Science Foundation of China (41871172), the Fundamental Research Funds for the Central Universities, China University of Geosciences (Wuhan) (GUGL170408); and the Key Laboratory of Meteorological Disaster of the Ministry of Education, Nanjing University of Information Science and Technology (No. KLME1506).

Acknowledgments: The authors would like to thank the Data Center for Eco-Environment Protection in the Qinghai Lake Basin (http://deep.qherc.org) for providing open-access data, and Jianxin Yang, Xun Liang, Jia Feng, and Guang Chen for their assistance. Additionally, the authors would like to thank anonymous reviewers for their helpful comments and suggestions.

Conflicts of Interest: The authors declare no conflict of interest. The funding sponsors had no role in the design of the study; in the collection, analyses, or interpretation of data; in the writing of the manuscript, or in the decision to publish the results.

\section{References}

1. Rodríguez-Echeverry, J.; Echeverría, C.; Oyarzún, C.; Morales, L.J.L.E. Impact of land-use change on biodiversity and ecosystem services in the Chilean temperate forests. Landsc. Ecol. 2018, 33, 439-453. [CrossRef]

2. Li, S.C.; Zhang, Y.L.; Wang, Z.F.; Li, L.H. Mapping human influence intensity in the Tibetan Plateau for conservation of ecological service functions. Ecosyst. Serv. 2018, 30, 276-286. [CrossRef]

3. Feddema, J.J.; Oleson, K.W.; Bonan, G.B.; Mearns, L.O.; Buja, L.E.; Meehl, G.A.; Washington, W.M. The Importance of Land-Cover Change in Simulating Future Climates. Science 2005, 310, 1674-1678. [CrossRef] [PubMed]

4. Newbold, T.; Hudson, L.N.; Hill, S.L.L.; Contu, S.; Lysenko, I.; Senior, R.A.; Börger, L.; Bennett, D.J.; Choimes, A.; Collen, B.J.N. Global effects of land use on local terrestrial biodiversity. Nature 2015, 520, 45-50. [CrossRef] [PubMed]

5. Li, S.; Bing, Z.; Jin, G. Spatially Explicit Mapping of Soil Conservation Service in Monetary Units Due to Land Use/Cover Change for the Three Gorges Reservoir Area, China. Remote Sens. 2019, 11, 468. [CrossRef]

6. Nowak, D.J.; Crane, D.E. Carbon storage and sequestration by urban trees in the USA. Environ. Pollut. 2002, 116, 381-389. [CrossRef] 
7. Rabbi, S.M.F.; Tighe, M.; Delgado-Baquerizo, M.; Cowie, A.; Robertson, F.; Dalal, R.; Page, K.; Crawford, D.; Wilson, B.R.; Schwenke, G.; et al. Climate and soil properties limit the positive effects of land use reversion on carbon storage in Eastern Australia. Sci. Rep. 2015, 5, 17866. [CrossRef]

8. Xu, L.; Yu, G.R.; He, N.P.; Wang, Q.F.; Gao, Y.; Wen, D.; Li, S.G.; Niu, S.L.; Ge, J.P. Carbon storage in China's terrestrial ecosystems: A synthesis. Sci. Rep. 2018, 8, 2806. [CrossRef]

9. Zhang, C.H.; Ju, W.M.; Chen, J.M.; Wang, X.Q.; Yang, L.; Zheng, G. Disturbance-induced reduction of biomass carbon sinks of China's forests in recent years. Environ. Res. Lett. 2015, 10, 114021. [CrossRef]

10. Seto, K.C.; Güneralp, B.; Hutyra, L.R. Global forecasts of urban expansion to 2030 and direct impacts on biodiversity and carbon pools. Proc. Natl. Acad. Sci. USA 2012, 109, 16083-16088. [CrossRef]

11. Zhao, S.Q.; Liu, S.G.; Sohl, T.; Young, C.; Werner, J. Land use and carbon dynamics in the southeastern United States from 1992 to 2050. Environ. Res. Lett. 2013, 8, 575-591. [CrossRef]

12. Fu, Y.C.; Lu, X.Y.; Zhao, Y.L.; Zeng, X.T.; Xia, L.L. Assessment Impacts of Weather and Land Use/Land Cover (LULC) Change on Urban Vegetation Net Primary Productivity (NPP): A Case Study in Guangzhou, China. Remote Sens. 2013, 5, 4125. [CrossRef]

13. Le Quéré, C.; Peters, G.P.; Andres, R.J.; Andrew, R.M.; Boden, T.A.; Ciais, P.; Friedlingstein, P.; Houghton, R.A.; Marland, G.; Moriarty, R. Global carbon budget 2013. Earth Syst. Sci. Data 2015, 7, 521-610. [CrossRef]

14. Fang, J.Y.; Chen, A.P.; Peng, C.H.; Zhao, S.Q.; Ci, L.J. Changes in forest biomass carbon storage in China between 1949 and 1998. Science 2001, 292, 2320-2322. [CrossRef] [PubMed]

15. Sohl, T.L.; Sleeter, B.M.; Zhu, Z.; Sayler, K.L.; Bennett, S.; Bouchard, M.; Reker, R.; Hawbaker, T.; Wein, A.; Liu, S.; et al. A land-use and land-cover modeling strategy to support a national assessment of carbon stocks and fluxes. Appl. Geogr. 2012, 34, 111-124. [CrossRef]

16. Tao, Y.; Li, F.; Liu, X.S.; Zhao, D.; Sun, X.; Xu, L.F. Variation in ecosystem services across an urbanization gradient: A study of terrestrial carbon stocks from Changzhou, China. Ecol. Mod. 2015, 318, 210-216. [CrossRef]

17. Yan, Y.; Zhang, C.; Hu, Y.F.; Kuang, W.H. Urban Land-Cover Change and Its Impact on the Ecosystem Carbon Storage in a Dryland City. Remote Sens. 2016, 8, 6. [CrossRef]

18. Steger, K.; Fiener, P.; Marvin-DiPasquale, M.; Viers, J.H.; Smart, D.R. Human-induced and natural carbon storage in floodplains of the Central Valley of California. Sci. Total Environ. 2019, 651, 851-858. [CrossRef]

19. Zhang, C.; Tian, H.; Chen, G.; Chappelka, A.; Xu, X.; Ren, W.; Hui, D.; Liu, M.; Lu, C.; Pan, S.; et al. Impacts of urbanization on carbon balance in terrestrial ecosystems of the Southern United States. Environ. Pollut. 2012, 164, 89-101. [CrossRef]

20. Leh, M.D.K.; Matlock, M.D.; Cummings, E.C.; Nalley, L.L. Quantifying and mapping multiple ecosystem services change in West Africa. Agric. Ecosyst. Environ. 2013, 165, 6-18. [CrossRef]

21. Sharp, R.; Tallis, H.; Ricketts, T.; Guerry, A.; Wood, S.; Chaplin-Kramer, R.; Nelson, E. VEST Version 3.2. 0 User's Guide; The Natural Capital Project. The Nature Conservancy, and World Wildlife Fund; Stanford University: Stanford, CA, USA; University of Minnesota: Minneapolis, MN, USA, 2015.

22. Rogers, K.; Kelleway, J.J.; Saintilan, N.; Megonigal, J.P.; Adams, J.B.; Holmquist, J.R.; Lu, M.; Schile-Beers, L.; Zawadzki, A.; Mazumder, D.; et al. Wetland carbon storage controlled by millennial-scale variation in relative sea-level rise. Nature 2019, 567, 91-95. [CrossRef] [PubMed]

23. Zhang, F.; Zhan, J.Y.; Zhang, Q.; Yao, L.; Liu, W. Impacts of land use/cover change on terrestrial carbon stocks in Uganda. Phys. Chem. Earth Parts A/B/C 2017, 101, 195-203. [CrossRef]

24. Schulz, K.; Guschal, M.; Kowarik, I.; Almeida-Cortez, J.S.; Sampaio, E.V.; Cierjacks, A. Grazing, forest density, and carbon storage: Towards a more sustainable land use in Caatinga dry forests of Brazil. Reg. Environ. Chang. 2018, 18, 1969-1981. [CrossRef]

25. Aryal, D.R.; Castro, H.G.; del Carmen García, N.; Ruiz, O.D.J.J.; Paniagua, L.F.M.; Trujillo, J.A.J.; Venegas, J.A.V.; Ruiz, R.P.; de Coss, A.L.; Hernández, F.G. Carbon storage potential in forest areas within a livestock system. Revista Mexicana Ciencias Forestales 2018, 9, 48.

26. Auerswald, K.; Fiener, P. Soil organic carbon storage following conversion from cropland to grassland on sites differing in soil drainage and erosion history. Sci. Total Environ. 2019, 661, 481-491. [CrossRef]

27. Bortolon, E.S.O.; Mielniczuk, J.; Tornquist, C.G.; Lopes, F.; Bergamaschi, H. Validation of the Century model to estimate the impact of agriculture on soil organic carbon in Southern Brazil. Geoderma 2011, 167-168, 156-166. [CrossRef] 
28. Gomes, L.C.; Faria, R.M.; de Souza, E.; Veloso, G.V.; Schaefer, C.E.G.R.; Filho, E.I.F. Modelling and mapping soil organic carbon stocks in Brazil. Geoderma 2019, 340, 337-350. [CrossRef]

29. Wang, B.; Waters, C.; Orgill, S.; Gray, J.; Cowie, A.; Clark, A.; Liu, D.L. High resolution mapping of soil organic carbon stocks using remote sensing variables in the semi-arid rangelands of eastern Australia. Sci. Total Environ. 2018, 630, 367-378. [CrossRef]

30. Minasny, B.; Setiawan, B.I.; Saptomo, S.K.; McBratney, A.B. Open digital mapping as a cost-effective method for mapping peat thickness and assessing the carbon stock of tropical peatlands. Geoderma 2018, 313, $25-40$. [CrossRef]

31. Lu, F.; Hu, H.; Sun, W.; Zhu, J.; Liu, G.; Zhou, W.; Zhang, Q.; Shi, P.; Liu, X.; Wu, X.; et al. Effects of national ecological restoration projects on carbon sequestration in China from 2001 to 2010. Proc. Natl. Acad. Sci. USA 2018, 115, 4039-4044. [CrossRef]

32. Fang, J.Y.; Guo, Z.D.; Hu, H.F.; Kato, T.; Muraoka, H.; Son, Y. Forest biomass carbon sinks in East Asia, with special reference to the relative contributions of forest expansion and forest growth. Glob. Chang. Biol. 2014, 20, 2019-2030. [CrossRef] [PubMed]

33. Almeida, C.M.; Gleriani, J.M.; Castejon, E.F.; Soares-Filho, B.S. Using neural networks and cellular automata for modelling intra-urban land-use dynamics. Int. J. Geogr. Inf. Syst. 2008, 22, 943-963. [CrossRef]

34. Xia, L.I.; Gar-On, Y.A. Neural-network-based Cellular Automata for Realistic and Idealized Urban Simulation. Acta Geogr. Sin. 2002, 57, 159-166.

35. Gong, J.; Li, J.Y.; Yang, J.X.; Li, S.C.; Tang, W.W. Land Use and Land Cover Change in the Qinghai Lake Region of the Tibetan Plateau and Its Impact on Ecosystem Services. Int. J. Environ. Res. Public Health 2017, 14, 818. [CrossRef] [PubMed]

36. Zhang, S.-Y.; Li, X.-Y.; Zhao, G.-Q.; Huang, Y.-M. Surface energy fluxes and controls of evapotranspiration in three alpine ecosystems of Qinghai Lake watershed, NE Qinghai-Tibet Plateau. Ecohydrology 2016, 9, 267-279. [CrossRef]

37. Government, Q.P. The Planning of the Main Functional Area of Qinghai Province Was Officially Released. Available online: http://www.gov.cn/xinwen/content_2660999.htm (accessed on 17 April 2014).

38. Xin, H. A Green Fervor Sweeps the Qinghai-Tibetan Plateau. Science 2008, 321, 633-635. [CrossRef] [PubMed]

39. Wang, X.; Bao, Y. Research on the methods of land use dynamic change research. Prog. Geogr. 1999, 18, 81-87.

40. Liu, X.P.; Liang, X.; Li, X.; Xu, X.C.; Ou, J.P.; Chen, Y.M.; Li, S.Y.; Wang, S.J.; Pei, F.S. A future land use simulation model (FLUS) for simulating multiple land use scenarios by coupling human and natural effects. Landsc. Urban Plan. 2017, 168, 94-116. [CrossRef]

41. Liang, X.; Liu, X.; Li, X.; Chen, Y.; Tian, H.; Yao, Y. Delineating multi-scenario urban growth boundaries with a CA-based FLUS model and morphological method. Landsc. Urban Plan. 2018, 177, 47-63. [CrossRef]

42. Xia, L.; Gar-Onyeh, A. Modelling sustainable urban development by the integration of constrained cellular automata and GIS. Int. J. Geogr. Inf. Syst. 2000, 14, 131-152.

43. Liang, X.; Liu, X.; Li, D.; Zhao, H.; Chen, G. Urban growth simulation by incorporating planning policies into a CA-based future land-use simulation model. Int. J. Geogr. Inf. Syst. 2018, 32, 2294-2316. [CrossRef]

44. Guan, Q.F.; Clarke, K.C. A general-purpose parallel raster processing programming library test application using a geographic cellular automata model. Int. J. Geogr. Inf. Syst. 2010, 24, 695-722. [CrossRef]

45. Li, X.; Yeh, A.G.-O. Cellular automata for simulating complex land use systems using neural networks. Geogr. Res. 2005, 24, 19-27.

46. Li, K.R.; Wang, S.Q.; Cao, M.K. Vegetation and soil carbon storage in China. Sci. China Ser. D 2003, 47, 72-80. [CrossRef]

47. Xie, X.L.; Sun, B.; Zhou, H.Z.; Li, Z.P.; Li, A.B. Organic carbon density and storage in soils of china and spatial analysis. Acta Pedol. Sin. 2004, 41, 35-43.

48. Xie, X.L.; Sun, B.; Zhou, H.Z.; Li, Z.P. Soil carbon stocks and their influencing factors under native vegetations in China. Acta Pedol. Sin. 2004, 41, 687-699.

49. Mei, H.; JinjJun, J.; Mingkui, C.; Kerang, L. Modeling study of vegetation shoot and root biomass in China. Acta Ecol. Sin. 2006, 26, 4156-4163.

50. Chuai, X.W.; Huang, X.J.; Zheng, Z.Q.; Zhang, M.; Liao, Q.L.; Lai, L.; Lu, J.Y. Land Use Change and Its Influence on Carbon Storage of Terrestrial Ecosystems in Jiangsu Province. Res. Sci. 2011, 33, 1932-1939. 
51. Tang, L.Y.; Duan, X.F.; Kong, F.J.; Zhang, F.; Zheng, Y.F.; Li, Z.; Mei, Y.; Zhao, Y.W.; Hu, S.J. Influences of climate change on area variation of Qinghai Lake on Qinghai-Tibetan Plateau since 1980s. Sci. Rep. 2018, 8, 7331. [CrossRef]

52. Liu, J.G.; Diamond, J. China's environment in a globalizing world. Nature 2005, 435, 1179. [CrossRef]

53. Qinghai Province Three-North Shelterbelt Project 40 Years of Artificial Afforestation 889,500 Hectares. Available online: http://www.forestry.gov.cn/main/72/content-1060041.html (accessed on 22 December 2017).

54. Luo, C.F.; Changjun, X.U.; You, H.Y. Analysis on grassland degradation in Qinghai Lake Basin during 2000-2010. Acta Ecol. Sin. 2013, 33, 4450-4459.

55. Nath, A.J.; Brahma, B.; Sileshi, G.W.; Das, A.K. Impact of land use changes on the storage of soil organic carbon in active and recalcitrant pools in a humid tropical region of India. Sci. Total Environ. 2018, 624, 908-917. [CrossRef] [PubMed]

56. Tardieu, L.; Roussel, S.; Thompson, J.D.; Labarraque, D.; Salles, J.M. Combining direct and indirect impacts to assess ecosystem service loss due to infrastructure construction. J. Environ. Manag. 2015, 152, 145-157. [CrossRef] [PubMed]

57. Quoc Vo, T.; Kuenzer, C.; Oppelt, N. How remote sensing supports mangrove ecosystem service valuation: A case study in Ca Mau province, Vietnam. Ecosyst. Serv. 2015, 14, 67-75. [CrossRef]

58. Cao, V.; Margni, M.; Favis, B.D.; Deschênes, L. Aggregated indicator to assess land use impacts in life cycle assessment (LCA) based on the economic value of ecosystem services. J. Cleaner Prod. 2015, 94, 56-66. [CrossRef]

59. He, C.Y.; Zhang, D.; Huang, Q.X.; Zhao, Y.Y. Assessing the potential impacts of urban expansion on regional carbon storage by linking the LUSD-urban and InVEST models. Environ. Modell. Softw. 2016, 75, 44-58. [CrossRef]

60. Li, Y.G.; Han, N.; Li, X.J.; Du, H.Q.; Mao, F.J.; Cui, L.; Liu, T.Y.; Xing, L.Q. Spatiotemporal Estimation of Bamboo Forest Aboveground Carbon Storage Based on Landsat Data in Zhejiang, China. Remote Sens. 2018, 10, 898. [CrossRef]

(C) 2020 by the authors. Licensee MDPI, Basel, Switzerland. This article is an open access article distributed under the terms and conditions of the Creative Commons Attribution (CC BY) license (http://creativecommons.org/licenses/by/4.0/). 